\title{
Tris(trimethylsilyl)methane is not an effective mediator of radical reactions
}

\author{
Alistair I. Longshaw, Michael W. Carland, Elizabeth H. Krenske, \\ Michelle L. Coote* and Michael S. Sherburn* \\ ARC Centre of Excellence for Free Radical Chemistry and Biotechnology, Research School of Chemistry, \\ Australian National University, Canberra ACT 0200, Australia
}

Received 15 May 2007; accepted 11 June 2007

Available online 15 June 2007

\begin{abstract}
The reductive dehalogenation of organohalides by tris(trimethylsilyl)methane has been re-investigated. Contrary to claims made in a recent publication (Tetrahedron Lett. 2006, 47, 5163-5165), (TMS) ${ }_{3} \mathrm{CH}$ does not reduce organohalides. In competition experiments between (TMS $)_{3} \mathrm{CH}$ and the poor chain mediator $\mathrm{Et}_{3} \mathrm{SiH}$, the latter performed the reduction. Computational investigations support these experimental findings and indicate that the $\mathrm{C}-\mathrm{H}$ bond of $(\mathrm{TMS})_{3} \mathrm{CH}$ is too strong for this compound to serve as an effective mediator of radical reactions.
\end{abstract}

(C) 2007 Published by Elsevier Ltd.

The introduction of tributyltin hydride as a mild and effective mediator of free radical chain reactions led to an upsurge in the development of new synthetic methods and strategies involving radical intermediates. ${ }^{1} \mathrm{Bu}_{3} \mathrm{SnH}$ is not, however, an ideal reagent. Organotin compounds are toxic ${ }^{2}$ and difficulties are often encountered in the separation of organotin by-products from the desired products of the radical reactions they mediate. Over the years several alternative reagents have been introduced, the most successful of which are Chatgilialoglu's tris(trimethylsilyl)silane ${ }^{3}$ and Barton's ethyl piperidinium hypophosphite (EPHP). ${ }^{4}$ These and related reagents can be used as replacements for $\mathrm{Bu}_{3} \mathrm{SnH}$ in many radical reactions. ${ }^{5}$ Nevertheless, (TMS) $)_{3} \mathrm{SiH}$ is expensive ${ }^{6}$ and not easy to prepare. ${ }^{7}$ In contrast, EPHP is cheap ${ }^{8}$ and easily made ${ }^{9}$ but must be used in large excess with copious amounts of initiator. We were excited, therefore, to read a recent publication in this Journal introducing a new radical reducing agent tris(trimethylsilyl)methane, (TMS) ${ }_{3} \mathrm{CH}^{10}{ }^{10}$ This compound appeared to offer significant advantages over existing reagents since, in addition to the fact that it is very easy to synthesize on multigram scale, ${ }^{11}$ the

\footnotetext{
Keywords: Radicals; Synthetic methods; Ab initio calculations.

* Corresponding authors. Tel.: +61 26125 3771; fax: +61 261250750

(M.L.C.); tel.: +61 26125 4988; fax: +61 261258114 (M.S.S.); e-mail addresses: mcoote@rsc.anu.edu.au; sherburn@rsc.anu.edu.au
}

reported rate constant for $\mathrm{H}$ atom transfer from (TMS) ${ }_{3} \mathrm{CH}$ to primary alkyl radicals is similar to that of (TMS) $)_{3} \mathrm{SiH}^{10}{ }^{10} \mathrm{We}$ were fascinated by the possibilities presented by (TMS $)_{3} \mathrm{CH}$ and embarked upon a program involving its use. Despite our best efforts, however, we have been unable to replicate the findings of the 2006 communication and report here the results of our own experimental and computational investigations with (TMS) $)_{3} \mathrm{CH}$, which we believe show that it is not an effective radical reducing agent.

Primary, secondary, and tertiary alkyl halides and aryl halides were reported to undergo reductive dehalogenation with (TMS $)_{3} \mathrm{CH}$ on heating in the presence of AIBN or 1,1'-azobis(cyclohexanecarbonitrile) (VAZO 88) or under unspecified photochemical conditions. We initially attempted to repeat the reported conversion of 1-bromoadamantane to adamantane using the thermal procedures described in the Letter (Scheme 1). ${ }^{10,12}$

$$
\underset{\mathrm{Br}}{+}(\mathrm{TMS})_{3} \mathrm{C}-\mathrm{H} \stackrel{(\mathrm{a})}{\longrightarrow} \text { no reaction }
$$

Scheme 1. Attempted radical reductions of 1-bromoadamantane. Reagents and conditions: (a) (TMS) ${ }_{3} \mathrm{CH}$ ( 2 mol equiv), benzene (substrate concn $0.1 \mathrm{M})$, AIBN or VAZO 88 (0.2-2 mol equiv), with or without anisole (internal standard), $80^{\circ} \mathrm{C}, 14-24 \mathrm{~h}$. 
Thus, AIBN (0.2 mol equiv) was added to a degassed mixture of 1-bromoadamantane and (TMS $)_{3} \mathrm{CH}$ ( 2 mol equiv) in benzene $(0.1 \mathrm{M}$ in substrate) and the resulting solution was heated to reflux for $14 \mathrm{~h}$. Despite many attempts with various batches of commercial ${ }^{13}$ and freshly prepare ${ }^{11}$ (TMS) ${ }_{3} \mathrm{CH}$, we found no reaction under these conditions. ${ }^{10,12}$ Furthermore, when the reaction was conducted with larger amounts of AIBN (up to 2 mol equiv) or VAZO (up to 2 mol equiv) in refluxing benzene, no adamantane was present in the reaction mixture. We replaced 1-bromoadamantane with iodobenzene and bromocyclohexane and obtained the same result: no products of reductive dehalogenation could be detected in the reaction mixtures by GC analysis and, in runs containing an internal GC standard, the $(\mathrm{TMS})_{3} \mathrm{CH}$ remained unchanged.

These results led us to suspect that an unidentified radical inhibitor was contaminating our reactions. Thus, a benzene solution of 1-bromoadamantane was exposed to equimolar amounts of (TMS) $)_{3} \mathrm{SiH}$ and (TMS) ${ }_{3} \mathrm{CH}$ under the standard conditions. This time, adamantane was formed cleanly (Scheme 2).

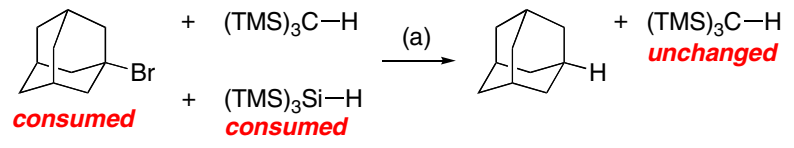

Scheme 2. Test for the presence of radical inhibitors. Reagents and conditions: (a) (TMS $)_{3} \mathrm{CH}$ ( 2 mol equiv), (TMS $)_{3} \mathrm{SiH}$ ( 2 mol equiv), benzene (substrate concn $0.1 \mathrm{M}$ ), AIBN ( $0.2 \mathrm{~mol}$ equiv), anisole (internal standard), $80^{\circ} \mathrm{C}, 14 \mathrm{~h}, 100 \%$ conversion.

Closer analysis of the product mixture revealed that $(\mathrm{TMS})_{3} \mathrm{CH}$ was unchanged and that (TMS) $)_{3} \mathrm{SiH}$ had been consumed. Whilst this result allayed our fears regarding inhibition of a radical chain process, we were cognizant of the fact that this outcome simply confirmed that (TMS $)_{3} \mathrm{SiH}$ was a more effective reducing agent than (TMS) ${ }_{3} \mathrm{CH}$. To shed light on the efficiency of (TMS) ${ }_{3} \mathrm{CH}$ as a reducing agent, a more stringent test was warranted. In the absence of polarity reversal catalysts, ${ }^{14}$ triethylsilane is known to be a poor radical reducing agent. It was reported ${ }^{10}$ that (TMS) ${ }_{3} \mathrm{CH}$ transfers a hydrogen atom to a primary alkyl radical significantly faster than triethylsilane. ${ }^{15}$ Thus, a competition experiment between (TMS) ${ }_{3} \mathrm{CH}$ and $\mathrm{Et}_{3} \mathrm{SiH}$ should result in the consumption of the former.

A solution of benzoyl peroxide ${ }^{16}$ ( 2 mol equiv) was added, via a syringe pump over $5 \mathrm{~h}$, to a solution of 1-bromoadamantane ( 1 mol equiv), (TMS $)_{3} \mathrm{CH}$ (10 equiv), and $\mathrm{Et}_{3} \mathrm{SiH}$ (10 equiv) in benzene $(0.1 \mathrm{M})$ at $80^{\circ} \mathrm{C}$ (Scheme 3). The progress of the reaction was monitored by GC using anisole as an internal standard. ${ }^{17}$ After $22 \mathrm{~h}$ at $80^{\circ} \mathrm{C}, \mathrm{GC}$ analysis revealed the presence of adamantane, decreased amounts of triethylsilane and 1-bromoadamantane, and no change in the amount of $(\mathrm{TMS})_{3} \mathrm{CH}$. We entertained the possibility that (TMS) ${ }_{3} \mathrm{CH}$ might somehow be catalyzing this reaction. When the experiment depicted in Scheme 3 was repeated without (TMS) ${ }_{3} \mathrm{CH}$, however, the same level of conversion of 1-bromoadamantane into adamantane was

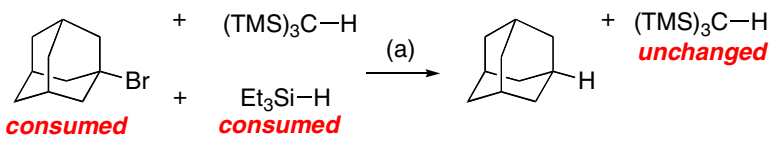

Scheme 3. Competition experiment between (TMS $)_{3} \mathrm{CH}$ and $\mathrm{Et}_{3} \mathrm{SiH}$. Reagents and conditions: (a) (TMS $)_{3} \mathrm{CH}$ (10 mol equiv), $\mathrm{Et}_{3} \mathrm{SiH}$ (10 mol equiv), benzene (substrate concn $0.1 \mathrm{M}),(\mathrm{BzO})_{2}(2 \mathrm{~mol}$ equiv, slow addition), anisole (internal standard), $80^{\circ} \mathrm{C}, 14 \mathrm{~h}, 27 \%$ conversion.

recorded. Furthermore, when the Scheme 3 competition experiment was repeated with the omission of $\mathrm{Et}_{3} \mathrm{SiH}$, no conversion of 1-bromoadamantane or $(\mathrm{TMS})_{3} \mathrm{CH}$ was observed.

We contemplated the possibility that the solvent was influencing the outcome of our reactions, since it is known that $\mathrm{Et}_{3} \mathrm{Si}^{-}$radicals add to benzene. ${ }^{18}$ Upon repeating the experiments described above in cyclohexane, however, similar results were obtained ${ }^{19}$ and no conversion of $(\mathrm{TMS})_{3} \mathrm{CH}$ was detected.

At this stage, we were confident that (TMS) ${ }_{3} \mathrm{CH}$ was inferior to $\mathrm{Et}_{3} \mathrm{SiH}$ as a radical reducing agent and that the procedures described in the 2006 communication ${ }^{10}$ were not reproducible. We reflected on the possibility that our reactions might be failing because they lacked a contaminant. Perhaps the original authors achieved successful transformations due to the presence of a catalyst of which they had no knowledge. We conducted a final set of experiments akin to those described above with added tert-dodecylthiol as a polarity reversal catalyst. ${ }^{20}$ Reactions involving $\mathrm{Et}_{3} \mathrm{SiH}$ in the presence of small amounts of thiol led to markedly faster conversions and higher conversions of the organohalide. To our dismay, $(\mathrm{TMS})_{3} \mathrm{CH}$ remained unchanged in all such tests.

Our experimental observations on the inefficiency of $(\mathrm{TMS})_{3} \mathrm{CH}$ as a chain carrier are supported by computational investigations. High-level ab initio calculations were used to model the radical reductive debromination of 1-bromoadamantane by the three chain carrier agents, according to the general pathway shown in Scheme 4. Relevant thermodynamic and kinetic parameters are given in Tables $1-3$.

From Table 1, it is seen that (TMS) ${ }_{3} \mathrm{CH}$ is the least susceptible of the three reagents toward initial hydrogen atom abstraction by the AIBN-derived 2-cyanopropyl radical. This lack of reactivity stems both from thermodynamic sources [the bond dissociation energy (BDE) $)^{21}$

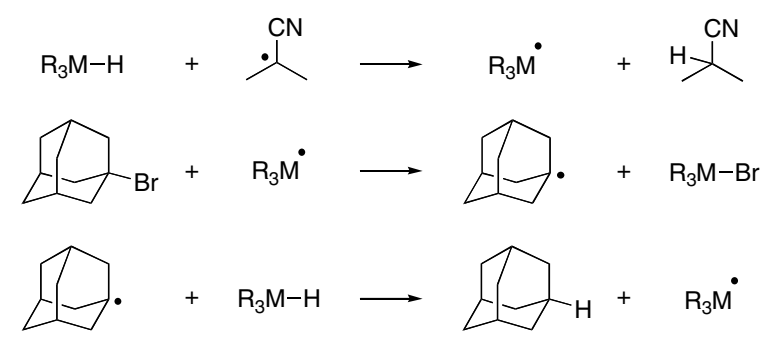

Scheme 4. Pathway modeled for radical reductive debromination of 1-bromoadamantane. $\mathrm{R}_{3} \mathrm{M}-\mathrm{H}=(\mathrm{TMS})_{3} \mathrm{C}-\mathrm{H},(\mathrm{TMS})_{3} \mathrm{Si}-\mathrm{H}$ or $\mathrm{Et}_{3} \mathrm{Si}-\mathrm{H}$. 
Table 1. Kinetics and thermodynamics of hydrogen atom abstraction from the various chain carriers at $353.15 \mathrm{~K}^{\mathrm{a}}$

\begin{tabular}{|c|c|c|c|c|c|c|}
\hline & & $\begin{array}{l}\Delta H^{\ddagger} / \Delta H \\
\left(\mathrm{~kJ} \mathrm{~mol}^{-1}\right)\end{array}$ & $\begin{array}{l}\Delta S^{\ddagger} / \Delta S \\
\left(\mathrm{~J} \mathrm{~mol}^{-1} \mathrm{~K}^{-1}\right)\end{array}$ & $\begin{array}{l}\Delta G^{\ddagger} / \Delta G \\
\left(\mathrm{~kJ} \mathrm{~mol}^{-1}\right)\end{array}$ & $Q$ & $\begin{array}{l}k \\
\left(\mathrm{~L} \mathrm{~mol}^{-1} \mathrm{~s}^{-1}\right) / \mathrm{K}\end{array}$ \\
\hline$(\mathrm{TMS})_{3} \mathrm{CH}+\cdot \mathrm{C}(\mathrm{CN}) \mathrm{Me}_{2} \rightarrow(\mathrm{TMS})_{3} \mathrm{C}^{\cdot}+\mathrm{H}-\mathrm{C}(\mathrm{CN}) \mathrm{Me}_{2}$ & $\begin{array}{l}\text { Rate }(k) \\
\text { Equilibrium }(K)\end{array}$ & $\begin{array}{l}38.7 \\
31.4\end{array}$ & $\begin{array}{r}-201.2 \\
7.4\end{array}$ & $\begin{array}{r}109.7 \\
28.8\end{array}$ & $\begin{array}{l}3.31 \\
-\end{array}$ & $\begin{array}{l}4.16 \times 10^{-2} \\
5.58 \times 10^{-5}\end{array}$ \\
\hline$(\mathrm{TMS})_{3} \mathrm{Si}-\mathrm{H}+{ }^{\cdot} \mathrm{C}(\mathrm{CN}) \mathrm{Me}_{2} \rightarrow(\mathrm{TMS})_{3} \mathrm{Si}^{\cdot}+\mathrm{H}-\mathrm{C}(\mathrm{CN}) \mathrm{Me}_{2}$ & $\begin{array}{l}\text { Rate }(k) \\
\text { Equilibrium }(K)\end{array}$ & $\begin{array}{r}4.1 \\
-27.2\end{array}$ & $\begin{array}{r}-170.4 \\
-8.0\end{array}$ & $\begin{array}{r}64.2 \\
-24.4\end{array}$ & $\begin{array}{l}1.63 \\
-\end{array}$ & $\begin{array}{l}1.09 \times 10^{5} \\
4.06 \times 10^{3}\end{array}$ \\
\hline 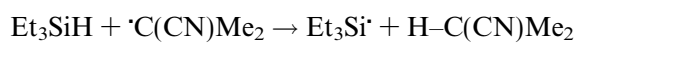 & $\begin{array}{l}\text { Rate }(k) \\
\text { Equilibrium }(K)\end{array}$ & $\begin{array}{l}40.6 \\
15.3\end{array}$ & $\begin{array}{r}-144.4 \\
-7.8\end{array}$ & $\begin{array}{l}91.6 \\
18.1\end{array}$ & $\begin{array}{l}4.29 \\
-\end{array}$ & $\begin{array}{l}2.54 \times 10^{1} \\
2.13 \times 10^{-3}\end{array}$ \\
\hline
\end{tabular}

${ }^{a}$ High-level ab initio calculations were performed at the G3(MP2)-RAD//B3-LYP/6-31G(d) level of theory. Partition functions and associated thermodynamic quantities were calculated using the standard formulae for the statistical thermodynamics of an ideal gas under the rigid rotor/ harmonic oscillator approximation, and the reaction rates incorporate Eckart tunneling corrections $(Q)$. For more details see the Supplementary data.

Table 2. Thermodynamics of bromine atom abstraction from 1-bromoadamantane by the various chain carrier radicals at $353.15 \mathrm{~K}^{\mathrm{a}}$

\begin{tabular}{|c|c|c|c|c|}
\hline & $\Delta H\left(\mathrm{~kJ} \mathrm{~mol}^{-1}\right)$ & $\Delta S\left(\mathrm{~J} \mathrm{~mol}^{-1} \mathrm{~K}^{-1}\right)$ & $\Delta G\left(\mathrm{~kJ} \mathrm{~mol}^{-1}\right)$ & $K$ \\
\hline$(\mathrm{TMS})_{3} \mathrm{C}^{\cdot}+$ adamantyl- $\mathrm{Br} \rightarrow(\mathrm{TMS})_{3} \mathrm{CBr}+$ adamantyl ${ }^{-}$ & 42.5 & -24.1 & 51.0 & $2.82 \times 10^{-8}$ \\
\hline$(\mathrm{TMS})_{3} \mathrm{Si}^{-}+$adamantyl- $\mathrm{Br} \rightarrow(\mathrm{TMS})_{3} \mathrm{SiBr}+$ adamantyl ${ }^{-}$ & -51.0 & -10.7 & -47.2 & $9.61 \times 10^{6}$ \\
\hline $\mathrm{Et}_{3} \mathrm{Si}^{-}+$adamantyl- $\mathrm{Br} \rightarrow \mathrm{Et}_{3} \mathrm{SiBr}+$ adamantyl & -108.4 & 4.0 & -109.8 & $1.72 \times 10^{16}$ \\
\hline
\end{tabular}

${ }^{a}$ High-level ab initio calculations were performed at a modified G3(MP2)-RAD'//B3-LYP/6-31G(d) level of theory. Partition functions and associated thermodynamic quantities were calculated using the standard formulae for the statistical thermodynamics of an ideal gas under the rigid rotor/harmonic oscillator approximation. For more details see the Supplementary data.

Table 3. Thermodynamics of hydrogen atom abstraction from the various chain carriers by the adamantyl radical at $353.15 \mathrm{~K}^{\mathrm{a}}$

\begin{tabular}{|c|c|c|c|c|}
\hline & $\Delta H\left(\mathrm{~kJ} \mathrm{~mol}^{-1}\right)$ & $\Delta S\left(\mathrm{~J} \mathrm{~mol}^{-1} \mathrm{~K}^{-1}\right)$ & $\Delta G\left(\mathrm{~kJ} \mathrm{~mol}^{-1}\right)$ & $K$ \\
\hline adamantyl $+(\text { TMS })_{3} \mathrm{CH} \rightarrow(\text { TMS })_{3} \mathrm{C}^{\cdot}+$ adamantane & -11.4 & 17.5 & -17.6 & $4.03 \times 10^{2}$ \\
\hline adamantyl $+(\text { TMS })_{3} \mathrm{SiH} \rightarrow(\mathrm{TMS})_{3} \mathrm{Si}^{*}+$ adamantane & -70.0 & 2.0 & -70.7 & $2.87 \times 10^{10}$ \\
\hline adamantyl $+\mathrm{Et}_{3} \mathrm{SiH} \rightarrow \mathrm{Et}_{3} \mathrm{Si}^{-}+$adamantane & -27.5 & 2.3 & -28.3 & $1.68 \times 10^{4}$ \\
\hline
\end{tabular}

${ }^{a}$ High-level ab initio calculations were performed at the G3(MP2)-RAD//B3-LYP/6-31G(d) level of theory. Partition functions and associated thermodynamic quantities were calculated using the standard formulae for the statistical thermodynamics of an ideal gas under the rigid rotor/ harmonic oscillator approximation. For more details see the Supplementary data.

for (TMS) ${ }_{3} \mathrm{CH}$ at $0 \mathrm{~K}$, at $401.5 \mathrm{~kJ} \mathrm{~mol}^{-1}$, is calculated to be some $57.5 \mathrm{~kJ} \mathrm{~mol}^{-1}$ greater than that for (TMS) ${ }_{3} \mathrm{SiH}$ $\left.\left(344.0 \mathrm{~kJ} \mathrm{~mol}^{-1}\right)^{22}\right]$, and from kinetic effects [(TMS $)_{3} \mathrm{CH}$ is calculated to be a factor of $3 \times 10^{6}$ slower as a hydrogen atom donor than its $\mathrm{Si}-\mathrm{H}$ analogue]. ${ }^{23}$ In comparison to the two TMS-substituted reagents, $\mathrm{Et}_{3} \mathrm{SiH}$ falls in an intermediate position, having a moderately low rate constant $^{24}$ and a reasonably unfavorable equilibrium constant for the initial hydrogen abstraction. The barrier $\left(\Delta H^{\ddagger}\right)$ for the initial hydrogen abstraction from (TMS $)_{3} \mathrm{CH}$ is very similar to that for $\mathrm{Et}_{3} \mathrm{SiH}$. However, the reagent $(\mathrm{TMS})_{3} \mathrm{CH}$ also suffers from entropic disadvantages, as in the transition state the distance between the abstracting and incipient radical centers is much smaller (and steric clashing is consequently more severe) than for the silanes: the distance C $\cdots \mathrm{H} \cdots \mathrm{C}$ in the transition state for hydrogen abstraction from (TMS) ${ }_{3} \mathrm{CH}$ is $2.8 \AA$, compared with $\mathrm{Si} \cdots \mathrm{H} \cdots \mathrm{C}$ distances of $3.2 \AA$ in the silane transition states.

The abstractions of bromine from 1-bromoadamantane are exothermic for $\mathrm{Et}_{3} \mathrm{Si}^{*}$ and $(\mathrm{TMS})_{3} \mathrm{Si}^{*}$ but endothermic for $(\mathrm{TMS})_{3} \mathrm{C}^{*}$ (Table 2). There is a large difference between the exothermicity of the reaction involving the carbon-centered radical with those involving the silyl radicals. This difference is related to the relative bond strengths of $\mathrm{Si}-\mathrm{Br}$ and $\mathrm{C}-\mathrm{Br}$ bonds and is in accord with the literature data for related compounds. For example, the $\mathrm{BDE}$ of the $\mathrm{Si}-\mathrm{Br}$ bond in $\mathrm{Me}_{3} \mathrm{Si}-\mathrm{Br}^{25}$ is $424.2 \mathrm{~kJ} \mathrm{~mol}^{-1}$, whereas the $\mathrm{BDE}$ of $\mathrm{Me}_{3} \mathrm{C}-\mathrm{Br}^{26}$ is only $292.9 \mathrm{~kJ} \mathrm{~mol}^{-1}$.

Hydrogen atom abstractions from the chain carriers by the adamantyl radical are also exothermic (Table 3). As expected, the enthalpies follow the same order as in the first step, with abstraction from the (TMS) ${ }_{3} \mathrm{CH}$ molecule least favorable. Our calculations are consistent with our experimental observations but are at odds with the reported $^{10}$ rate data for $\mathrm{H}$ atom abstraction from $(\mathrm{TMS})_{3} \mathrm{CH}$ by primary alkyl radicals.

We believe that our experimental and computational results demonstrate that chain-carrier efficiency varies in the order $(\mathrm{TMS})_{3} \mathrm{SiH}>\mathrm{Et}_{3} \mathrm{SiH} \gg(\mathrm{TMS})_{3} \mathrm{CH}$. The distinction between the two $\mathrm{SiH}$ reagents may be attributed predominantly to the kinetic attributes of hydrogen atom abstraction. On the other hand, for $(\mathrm{TMS})_{3} \mathrm{CH}$ there is not only a higher barrier to the initial $\mathrm{C}-\mathrm{H}$ abstraction, but the subsequent bromine abstraction is even less energetically favorable. We therefore conclude that tris(trimethylsilyl)methane is not an effective radical reducing agent. ${ }^{27}$ 


\section{Acknowledgements}

We thank the Australian Research Council for funding and APAC for generous allocations of computing time. Thanks also to Melissa Laws, Andrew Donohue, and Leigh Ford (University of Melbourne) for drawing our attention to the original report.

\section{Supplementary data}

Supplementary data associated with this article (computational methods and tables of geometries and total energies) can be found, in the online version, at doi:10.1016/j.tetlet.2007.06.055.

\section{References and notes}

1. (a) Neumann, W. P. Synthesis 1987, 665-683; (b) Pereyre, M.; Quintard, J.-P.; Rahm, A. Tin in Organic Synthesis; Butterworths: London, 1987; (c) RajanBabu, T. V. In Encyclopedia of Reagents for Organic Synthesis; Paquette, L., Ed.; John Wiley \& Sons: Chichester, 1995; Vol. 7, pp 5016-5023; (d) Davies, A. G. Organotin Chemistry, 2nd ed.; Wiley-VCH: Weinheim, 2004.

2. (a) Ingham, R. K.; Rosenberg, S. D.; Gilman, H. Chem. Rev. 1960, 60, 459-539; (b) Boyer, I. J. Toxicology 1989, 55, 253-298.

3. (a) Chatgilialoglu, C.; Griller, D.; Lesage, M. J. Org. Chem. 1988, 53, 3641-3642; (b) Chatgilialoglu, C.; Ferreri, C.; Gimisis, T. In The Chemistry of Organic Silicon Compounds; Rappoport, Z., Apeloig, Y., Eds.; John Wiley \& Sons: Chichester, 1998; Vol. 2, Part 2, pp 1539-1579; (c) Chatgilialoglu, C.; Schiesser, C. H.. In The Chemistry of Organic Silicon Compounds; Rappoport, Z., Apeloig, Y., Eds.; John Wiley \& Sons: Chichester, 2001; Vol. 3, pp 341-390; (d) Chatgilialoglu, C. In Radicals in Organic Synthesis; Renaud, P., Sibi, M. P., Eds.; Wiley-VCH: Weinheim, 2001; Vol. 1, pp 28-49.

4. (a) Barton, D. H. R.; Jang, D. O.; Jaszberenyi, J. C. Tetrahedron Lett. 1992, 33, 5709-5712; (b) Barton, D. H. R.; Jang, D. O.; Jaszberenyi, J. C. J. Org. Chem. 1993, 58, 6838-6842.

5. (a) Baguley, P. A.; Walton, J. C. Angew. Chem., Int. Ed. 1998, 37, 3072-3082; (b) Studer, A.; Amrein, S. Synthesis 2002, 835-849.

6. Tris(trimethylsilyl)silane, Aldrich, Order number $=$ 360,716 , CAS number $=1873-77-4,5 \mathrm{~g}=\$ 136.00$ AUD (2007-2008 catalog).

7. Dickhaut, J.; Giese, B. Org. Synth. 1992, 70, 164-168.

8. 1-Ethyl piperidine hypophosphite, Aldrich, Order number $=436,178$, CAS number $=145060-63-5,5 \mathrm{~g}=\$ 29.00$ AUD (2007-2008 catalog).

9. Fairlamb, I. J. S.; Grant, S.; Whitwood, A. C.; Whitthall, J.; Batsanov, A. S.; Collings, J. C. J. Organomet. Chem. 2005, 690, 4462-4477.

10. Perchyonok, V. T. Tetrahedron Lett. 2006, 47, 5163-5165.

11. Avent, A. G.; Eaborn, C.; Hitchcock, P. B.; Lawless, G. A.; Lickiss, P. D.; Mallien, M.; Smith, J. D.; Webb, A. D.; Wrackmeyer, B. J. Chem. Soc., Dalton Trans. 1993, 32593264.

12. In the text of the Letter ${ }^{10}$ the reduction is reported to occur over $3 \mathrm{~h}$. In the detailed procedure, however, (footnotes 8 and 9 of the Letter ${ }^{10}$ ) the reaction time is reported to be $12 \mathrm{~h}$.
13. Tris(trimethylsilyl)methane, Aldrich, Order number $=$ 302,600 , CAS number $=1068-69-5, \quad 1 \mathrm{~g}=\$ 100 \quad$ AUD (2007-2008 catalog).

14. Allen, R. P.; Roberts, B. P.; Willis, C. R. J. Chem. Soc., Chem. Commun. 1989, 1387-1388.

15. Kinetic data is taken from Ref. 10. The rate constants cited in Ref. 10 for $\mathrm{H}$ atom abstraction from (TMS) $)_{3} \mathrm{SiH}$ and $\mathrm{Et}_{3} \mathrm{SiH}$ by primary alkyl radicals are erroneously reported as $11 \times 10^{-5} \mathrm{~L} \mathrm{~mol}^{-1} \mathrm{~s}^{-1}$ and $0.04 \times 10^{-5} \mathrm{~L} \mathrm{~mol}^{-1} \mathrm{~s}^{-1}$, respectively. The correct values are $3.7 \times 10^{5} \mathrm{~L} \mathrm{~mol}^{-1} \mathrm{~s}^{-1}$ and $6.4 \times 10^{2} \mathrm{~L} \mathrm{~mol}^{-1} \mathrm{~s}^{-1}$, respectively: see Refs. 23 and 24.

16. No reaction was observed upon attempted initiation of the radical reaction with either AIBN or VAZO 88.

17. Experimental procedure: A solution of 1-bromoadamantane $(20 \mathrm{mg}, 0.09 \mathrm{mmol})$, anisole $(10 \mu \mathrm{L})$, triethylsilane $(150 \mu \mathrm{L}, 0.9 \mathrm{mmol}, 10 \mathrm{~mol}$ equiv), and/or tris(trimethylsilyl)methane $(260 \mu \mathrm{L}, 0.9 \mathrm{mmol}, 10 \mathrm{~mol}$ equiv) in benzene $(1 \mathrm{~mL})$ was heated to $80^{\circ} \mathrm{C}$. A solution of benzoyl peroxide $(50 \mathrm{mg}, 0.2 \mathrm{mmol}, 2$ equiv) in benzene $(1 \mathrm{~mL})$ was added, via syringe pump, over $5 \mathrm{~h}$. A diluted sample of the reaction mixture was injected directly into an Agilent 6850 series GC instrument fitted with an Agilent 19091 J-233E, HP5 5\% phenyl methyl siloxane column (capillary size: $30.0 \mathrm{~m} \times 250 \mu \mathrm{m} \times 1.00 \mu \mathrm{m}$ ).

18. Griller, D.; Marriott, P. R.; Nonhebel, D. C.; Perkins, M. J.; Wong, P. C. J. Am. Chem. Soc. 1981, 103, 77617763.

19. Higher conversions of 1-bromoadamantane to adamantane were obtained with $\mathrm{Et}_{3} \mathrm{SiH}$ in cyclohexane.

20. Roberts, B. P. Chem. Soc. Rev. 1999, 28, 25-35.

21. G3(MP2)-RAD values at $0 \mathrm{~K}$, incorporating scaled B3LYP/6-31G(d) zero-point energies (see Supplementary data).

22. This value compares favorably with the experimental BDE for (TMS) ${ }_{3} \mathrm{Si}-\mathrm{H}$ of $347 \mathrm{~kJ} \mathrm{~mol}^{-1}$ : Becerra, R.; Walsh, R.. In The Chemistry of Organic Silicon Compounds; Rappoport, Z., Apeloig, Y., Eds.; John Wiley \& Sons: Chichester, 1998; Vol. 2, Part 1, pp 153-180. The experimental $\mathrm{BDE}$ for $\mathrm{Et}_{3} \mathrm{Si}-\mathrm{H}$ (reported in the same paper) is $392 \mathrm{~kJ} \mathrm{~mol}^{-1}$. To our knowledge the BDE for (TMS) ${ }_{3} \mathrm{C}-$ $\mathrm{H}$ has not been reported.

23. Experimental rate constants (at $298 \mathrm{~K}$ ) are 3.7, 1.4, and $2.6 \times 10^{5} \mathrm{~L} \mathrm{~mol}^{-1} \mathrm{~s}^{-1}$ for $\mathrm{H}$ atom abstraction from $(\mathrm{TMS})_{3} \mathrm{Si}-\mathrm{H}$ by primary, secondary, and tertiary alkyl radicals, respectively: Chatgilialoglu, C.; Dickhaut, J.; Giese, B. J. Org. Chem. 1991, 56, 6399-6403, Our calculated rate constant for $\mathrm{H}$ atom abstraction from $(\mathrm{TMS})_{3} \mathrm{Si}-\mathrm{H}$ by the 2-cyanopropyl radical of $1.09 \times 10^{5} \mathrm{~L} \mathrm{~mol}^{-1} \mathrm{~s}^{-1}$ (Table 1) is in good agreement with this experimental value.

24. The experimental rate constants (at $298 \mathrm{~K}$ ) for $\mathrm{H}$ atom abstraction from $\mathrm{Et}_{3} \mathrm{Si}-\mathrm{H}$ by a primary alkyl radical is $6.4 \times 10^{2} \mathrm{~L} \mathrm{~mol}^{-1} \mathrm{~s}^{-1}$ : Chatgilialoglu, C.; Ferreri, C.; Lucarini, M. J. Org. Chem. 1993, 58, 249-251, Our calculated rate constant for $\mathrm{H}$ atom abstraction from $\mathrm{Et}_{3} \mathrm{Si}-\mathrm{H}$ by the 2-cyanopropyl radical of $2.54 \times 10^{1} \mathrm{~L} \mathrm{~mol}^{-1} \mathrm{~s}^{-1}$ (Table 1) is in good agreement with this experimental value.

25. Dávalos, J. Z.; Baer, T. J. Phys. Chem. A 2006, 110, 8572 8579.

26. Pedley, J. B.; Naylor, R. D.; Kirby, S. P. Thermochemical Data of Organic Compounds, 2nd ed.; Chapman and Hall: New York, 1986.

27. There remains the possibility that a contaminant other than those tested here is facilitating the transformations described in the 2006 communication. 